\title{
Implantação do Programa GEFIP em uma Instituição Pública do Estado de São \\ Paulo: um relato de experiência
}

\section{Glaucia Mayumi Hayama Menezes da Silva}

Nilsa Mara de Arruda Yamanaka

\section{Conceito do GEFIP:}

Gestão do Fluxo Interno de Pacientes (GEFIP) foi um programa criado para melhorar os processos do Fluxo do Paciente (admissão até a alta hospitalar), garantindo a Qualidade e Segurança no atendimento da assistência ao paciente.

\section{Objetivo:}

Melhorar os processos do Fluxo do Paciente com a redução do tempo de permanência do paciente no ambiente hospitalar, aumentar a disponibilidade de leitos, melhorar a qualidade de previsão de altas pela equipe médica e eliminar os desperdícios para otimizar os tempos das etapas do processo no Fluxo do Paciente.

\section{Metodologia:}

Lean é uma filosofia da gestão inspirada em práticas e resultados do Sistema Toyota focada na redução dos desperdícios e melhoria contínua dos processos. Esta, foi a ferramenta escolhida para o GEFIP identificar os "gargalos" nas etapas do Fluxo do Paciente, desde a admissão até a alta hospitalar, elaborar ações para mitigar os desperdícios encontrados e agilizar o processo de admissão e altas dos pacientes.

\section{Reuniões:}

As reuniões foram realizadas mensalmente e discutidas as problemáticas apresentadas no Fluxo do Paciente, no qual, conseguimos melhorar muito o nosso tempo de alta dos pacientes através do trabalho árduo realizado em equipe por diversas áreas como: Médica, Enfermagem, Serviço Social, Tecnologia da Informação, Hotelaria, Logística, Farmácia, Gestão de Leitos e Oficial Administrativo, conseguindo 0 resultado por meio de indicadores acompanhados no GEFIP, como o tempo de alta médica, o tempo da saída do paciente, o tempo da higienização, o tempo entre o término da higienização e uma nova admissão.

\section{Membros do GEFIP:}

A equipe é formada por áreas estratégicas que compõem o processo do Fluxo do Paciente na instituição, como a equipe Médica, Enfermagem, Hotelaria, Tecnologia da Informação, GILAC, GAPI, Assistentes Diretoria Executiva, Serviço Social, Gestão da Informação em Saúde e Qualidade e Segurança do Paciente.

\section{Ações realizadas em 2018:}

Em 2018, tivemos 30 projetos Lean na instituição, sendo 7 projetos interligados ao GEFIP, que foram acompanhados e monitorados pelo grupo, obtendo ações como a alteração no fluxo do processo de alta médica, orientação da equipe de enfermagem e hotelaria para digitar o código de liberação dos leitos para melhorar o tempo de higienização dos leitos para uma nova admissão, reduzir o tempo de aceites dos pacientes do CAIO para internação pela especialidade médica e identificar o motivo pelo qual, a alta permanência do paciente no CAIO.

\section{Experiência:}

Com a criação do GEFIP, foi possível identificar os "gargalos" no Fluxo do Paciente e por ser composta por áreas estratégicas, facilitou a comunicação e ações a serem atuadas na etapa do processo do Fluxo do Paciente, no qual, a metodologia Lean fez olhar o processo de forma diferenciada e ampliar a visão e entendimento dos profissionais da importância em agilizar as altas, aumentar o giro dos leitos e realizar novas admissões, garantindo a Segurança do Paciente em todas as etapas do processo.

Diante de todo o trabalho realizado e obtendo o foco no processo de alta dos pacientes, tivemos 0 apoio dos Coordenadores Médico Cirúrgico e Clínico, que com a atuação deles, juntamente com a equipe multiprofissional conseguimos almejar o nosso objetivo com êxito e sucesso.

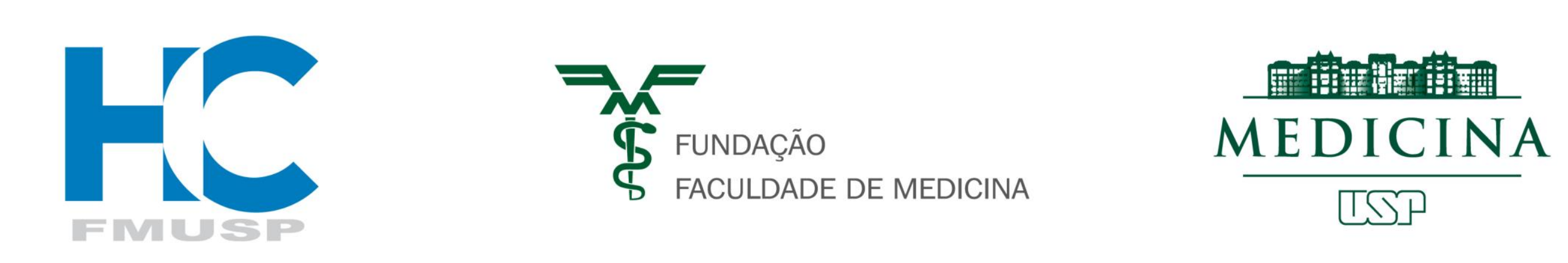

